\title{
Instance-based categorization: Automatic versus intentional forms of retrieval
}

\author{
ANDREW NEAL, BERYL HESKETH, and SALLY ANDREWS \\ University of New South Wales, Sydney, Australia
}

\begin{abstract}
Two experiments are reported which attempt to disentangle the relative contribution of intentional and automatic forms of retrieval to instance-based categorization. A financial decision-making task was used in which subjects had to decide whether a bank would approve loans for a series of applicants. Experiment 1 found that categorization was sensitive to instance-specific knowledge, even when subjects had practiced using a simple rule. L. L. Jacoby's (1991) process-dissociation procedure was adapted for use in Experiment 2 to infer the relative contribution of intentional and automatic retrieval processes to categorization decisions. The results provided (1) strong evidence that intentional retrieval processes influence categorization, and (2) some preliminary evidence suggesting that automatic retrieval processes may also contribute to categorization decisions.
\end{abstract}

Performance on many complex tasks requires one to respond adaptively to new examples of known classes of objects or events. Such adaptive responding requires the generalization of knowledge acquired from previously encountered instances to the new instance. Although the importance of analytic forms of thought for generalization have traditionally been emphasized, the role of nonanalytic processes has recently become a topic of increased interest in a number of areas of psychology (see, e.g., Hayes \& Broadbent, 1988; Jacoby \& Brooks, 1984; Klein \& Calderwood, 1991). The term nonanalytic is used in two senses: first, to refer to processes that make use of knowledge derived from individual learning episodes, rather than knowledge represented in an abstract form; and second, to refer to processes that seem "implicit [and] intuitive" rather than "deliberate, verbal, [and] analytic" (Brooks, 1978, p. 207; Kemler Nelson, 1984). The present study investigated whether knowledge derived from individual learning episodes influenced learning, and the extent to which these influences were "implicit and intuitive" rather than deliberate and controlled.

\section{Instance-Based Models of Learning}

Because nonanalytic approaches to learning emphasize the importance of knowledge derived from individual learning episodes, they fall under the general class of instance-based models of learning (Estes, 1986). Instance models have been proposed for such diverse phenomena as categorization (Brooks, 1987; Hintzman, 1986; Medin \& Schaffer, 1978; Nosofsky, 1986; Ross,

This research was carried out with the support of an Australian postgraduate research award to the first author. We thank Brian Ross, Larry Jacoby, and one anonymous reviewer for their helpful comments on an earlier version of this article. Address reprint requests to A. Neal, Department of Psychology, The University of Queensland, QLD 4072, Australıa (e-mall, bhesketh(a)bunyip.bhs.mq.edu.au).
Perkins, \& Tenpenny, 1990), social cognition (E. R. Smith \& Zarate, 1990), problem solving (Ross, 1987), automaticity (Logan, 1988), repetition priming (Logan, 1990), and perceptual identification (Nosofsky, 1986). Common to all instance models is the assumption that each instance or processing episode is stored as a separate trace, and that generalization is performed by reference to these stored instances. Access to stored instances depends on the similarity between the current instance and the stored instances. Some models assume that responses are based on the analogy between the test instance and specific individual instances that have been retrieved (e.g., Brooks, 1978; Ross, 1987; Ross et al., 1990), whereas others assume that responses are a function of the degree of match between the test instance and a pool of instances retrieved from memory, where the information in this pool represents a weighted average of all instances stored in memory (Estes, 1986; Hintzman, 1986; Medin \& Schaffer, 1978; Nosofsky, 1986).

A number of researchers (e.g., Allen \& Brooks, 1991; Jacoby, 1983; Kahneman \& Miller, 1986; Medin \& Schwanenflugel, 1981; Vokey \& Brooks, 1992; Wattenmaker, 1991; Whittlesea \& Brooks, 1988) have provided evidence supporting general instance models. One of the approaches that is used to evaluate instance models is to test whether the idiosyncratic details of individual learning episodes exert an influence on performance, even when learners have had sufficient opportunity to develop a body of abstract knowledge. Using this approach, Allen and Brooks (1991) designed a set of stimuli with a simple, perfectly predictive three-feature categorization rule. The training items consisted of novel animals which were relatively rich in idiosyncratic contextual detail. Each new test item was similar to one of the training items. The new item could be either in the same category as the training item that it resembled (Good analogy) or in the category opposite that of the training item that it resembled ( $B a d$ analogy). For Good 
analogies, therefore, similarity to a training instance predicted the same response as that predicted by the categorization rule. For Bad analogies, however, similarity and the rule predicted opposite responses. The basic finding was that, even when subjects were given extensive practice with the categorization rule, categorization was less accurate for Bad analogies than for the Good analogies. The impaired performance on Bad analogies was attributed to the similarity of the test instances to training instances, and was interpreted as showing that instance knowledge could influence categorization even when subjects had access to a well-learned rule. Similar findings have been reported by Brooks, Norman, and Allen (1991) in relation to general practitioners' diagnoses of dermatological lesions. Of particular interest is Allen and Brooks's (1991) finding that the influence of previously encountered instances was relatively insensitive to intentional control. Performance on Bad analogies was impaired even when subjects were alerted to the existence of Bad analogies and were instructed to avoid making errors on these items. In addition, postexperimental interviews suggested that a substantial proportion of subjects were unaware of the source of the errors. These data suggest that the influence of instances on categorization may be insensitive to intentional control. Performance could, therefore, be argued to be nonana"lytic in both senses of the term; it is influenced by the details of specific learning episodes, and the influence of these episodes appears "implicit and intuitive" rather than deliberate and controlled.

\section{Intentional and Automatic Learning}

Sensitivity to intentional control is central to most definitions of automaticity. Although standard definitions of automaticity rest on at least three criteria-insensitivity to intentional control, insensitivity to capacity limitations, and absence of awareness (see, e.g., Hasher \& Zacks, 1979; Shiffrin \& Schneider, 1977)—all three criteria are rarely met simultaneously (see Bargh, 1989). Jacoby (1991) has, therefore, proposed that automaticity be defined solely in terms of sensitivity to intentional control. While this definition limits the use of the term automaticity, it ensures that the construct can be precisely operationalized and avoids the problem of nonconvergence among other criteria (cf. Jacoby, Toth, \& Yonelinas, 1993). Using Jacoby's (1991) definition, the evidence obtained by Allen and Brooks (1991) demonstrating that subjects were unable to control the intrusion of prior experience suggests that the retrieval of instance knowledge can occur automatically.

There is relatively strong evidence from the episodic memory literature to support the contention that instance retrieval can occur automatically. This literature also represents a source of potentially useful techniques for diagnosing the automaticity of instance effects within categorization. One form of evidence that instance retrieval can be automatic derives from research using indirect tests of memory in both normal and amnesic pop- ulations. This research has demonstrated that prior experience can facilitate performance on a number of tasks despite an inability to recall or recognize that experience (see Richardson-Klavehn \& Bjork, 1988, and Schacter, 1987, for reviews), and that this facilitation can occur independently of intention to retrieve and even without conscious awareness of retrieval (Schacter, Bowers, \& Booker, 1989).

When categorical responses are based on instance knowledge, the categorization task can be viewed as an indirect test of memory, because categorization tasks do not explicitly require subjects to recollect the training items. Examining the relationship between categorization tasks and direct measures of memory, such as recognition, provides one means of inferring the nature of the retrieval processes underlying instance effects in categorization. The logic of this approach suggests that if performance on a categorization task is correlated with performance on a direct memory task, then both tasks may involve the same types of (presumably explicit) processing. However, a lack of a correlation between performance in the two tasks implies that they rely on different processes, and that categorization does not necessarily rely on conscious recollection. Experiment 1 of the present paper tests this approach. Unfortunately, previous studies that have tested the relationship between direct tests of memory and categorization (McAndrews \& Moscovitch, 1985; Metcalfe \& Fisher, 1986) are not particularly informative in the current context, because they were designed to test whether categorization was based on instance or abstract knowledge rather than to examine the nature of the retrieval process itself (see Nosofsky, 1988, for a critique of this approach).

Dual-process theories of recognition (e.g., Jacoby, 1991; Jacoby \& Dallas, 1981; Mandler, 1980) represent an alternate source of evidence, suggesting that instance retrieval can be automatic, and may provide an alternative approach for testing whether instance retrieval in categorization tasks can be automatic. Dual-process theories of recognition assume that both intentional and automatic forms of retrieval influence recognition. Conscious recollection is an intentional basis for recognition judgments and is sensitive to dual-task interference and intentional control. Familiarity is an automatic basis for recognition judgments, and has been shown to be relatively insensitive to dual-task interference and intentional control (Jacoby, 1991; Jacoby, Woloshyn, \& Kelley, 1989). If both intentional and automatic forms of retrieval can influence performance on recognition memory tasks, then there is a strong case for suggesting that both forms of retrieval may contribute to instance effects in categorization. Categorization decisions that are based on the abstraction of categorical information from specific past instances (Ross et al., 1990) probably require the conscious recollection of those instances. Nosofsky (1988) and Jacoby (1991), on the other hand, draw parallels between the nature of familiarity effects in recognition and instance-based categorization, sug- 
gesting that both involve global matching with a pool of retrieved instances. If familiarity and pooled knowledge forms of categorization share the same retrieval mechanism, then it appears reasonable to propose that pooled knowledge forms of categorization, like familiarity, may be automatic.

Evidence suggesting that both intentional and automatic processes influence recognition judgments, and possibly also categorization judgments, highlights one of the major problems with testing for dissociations between direct tests of memory and categorization. A relationship between a direct test of memory and categorization does not necessarily indicate that categorization involves conscious recollection. Categorization and recognition could be related either because both involve conscious recollection or because both involve an automatic form of retrieval. In Experiment 2, we avoided these problems by using methodology derived from dualprocess theories of recognition to separately estimate the contribution of intentional and automatic retrieval processes in categorization.

\section{EXPERIMENT 1}

In Experiments 1 and 2, the paradigm used by Allen and Brooks (1991) was adapted in order to examine the influence of prior instances and declarative rule knowledge on the learning of a category. Allen and Brooks demonstrated that even when subjects were given practice with a simple, perfectly predictive categorization rule, similarity to previous instances still strongly influenced performance. Similarity and categorical status were manipulated independently in the test phase by generating two types of transfer items-Good analogies and Bad analogies. The transfer items were each identical to separate training items on all but one dimension, which was switched to its opposite value. The switching of the key feature resulted in the items' either staying in the same category as the item they resembled (Good analogies) or shifting to the opposite category to the item they resembled (Bad analogies). If similarity to previous instances influences categorization, then the similarity of the Bad analogies to training items from the opposite category should result in an elevated categorization error rate relative to that for Good analogies. Allen and Brooks found that the error rate for Bad analogies was significantly greater than that for Good analogies and previously seen (Old) items, suggesting that similarity to prior instances influenced categorization.

The present study was based on Allen and Brooks (1991), but the stimuli and design were modified to make the learning task resemble a naturally occurring learning task in a work environment. Rather than pictures of artificial animals, the stimuli were descriptions of people who had applied to a finance company for a loan to establish small businesses. The two categories represented people whose loan applications were approved and people whose applications were rejected. The information was presented in the form of verbal narratives paired with color slides of faces. The presentation of the information verbally, rather than as pictures, meant that the information was presented sequentially, in the form of a list of features. Previous studies have found that presenting stimuli in the form of feature lists (Allen \& Brooks, 1991, Experiment 2) eliminated the effects of Bad analogies. Brooks and his colleagues (e.g., Reghr \& Brooks, 1993) argued that the elimination of Bad analogy effects occurred because the particular form of sequential presentation reduced the perceptual distinctiveness of the individual stimuli and made the dimensional structure of the stimuli salient. Although the current stimuli were presented as a sequential list of features, the features were idiosyncratic, they were embedded in a verbal narrative, and they were accompanied by visual cues (the faces) in order to render each item individually distinctive and to encourage nonanalytic processing.

It has been argued that the "ecological significance" of an instance-based learning mechanism derives from the fact that it allows learning to occur under incidental conditions, which are typical of real-world learning environments (Brooks, 1987; Kemler Nelson, 1984; Wattenmaker, 1991). The incidental learning conditions that are commonly used involve intentional memorization of the training instances (e.g., Brooks, 1978). Memorization tasks, however, are not neutral because they bias processing in favor of instance representation (Reber \& Allen, 1978). Furthermore, if learning is instance based, then a memorization task is an intentional learning task, and not incidental. The current experiment, therefore, included two Nonrule learning groups in addition to the group given practice at applying the rule (the Rule group). The Nonrule groups included a group given memorization instructions (the Exemplar group) and a group given incidental learning instructions emphasizing impression formation rather than rule application or memorization (the Incidental group). Finally, measures of cued recall of separate feature values and declarative knowledge of the features defining the rule were included to evaluate the degree to which these measures predicted categorization performance across different learning conditions and analogy types.

It was expected that despite the changes in the nature of the stimuli, the basic finding of Allen and Brooks would be replicated, and that performance on the Bad analogies would be impaired relative to the Good analogies. Impairment of Bad analogy performance strongly suggests that similarity influences categorization. Checks were made to ensure that subjects were not simply classifying stimuli on the basis of single features (criterial rules), which would have confounded the conclusions drawn from the data. Correlations between performance on different test measures would suggest that similar processes were involved in the tasks, while null findings would suggest that the processes differed (Hintzman, 1990; Nosofsky, 1988). Specifically, if categorization is dependent on the application of the rule, then perfor- 
mance should be correlated with the declarative knowledge and cued recall measures, because all three measures involve analytic processing of individual feature values in a similar manner. Low correlations between categorization performance and declarative knowledge would indicate that categorization performance was not dependent on use of the rule. The cued recall measure provides preliminary evidence regarding the nature of instance retrieval. If other evidence were to indicate that categorization was influenced by similarity and not by the rule, then a high correlation between categorization and cued recall might indicate that instance effects were due to the explicit recollection of instances.

\section{Method}

Design. A $3 \times(3)$ design was used. The between-groups factor represented the instructions given to subjects. The three instructional groups were the Incidental, Exemplar, and Rule groups. The within-groups factor was analogy type. The three types of items were Old items, Good analogies, and Bad analogies.

Subjects. Thirty-seven first-year psychology students ( 8 males and 29 females) volunteered to participate in return for course credit.

Stimuli and Materials. The exemplars were generated using a modified version of the abstract category structure used by Allen and Brooks (1991; see Appendix A). The information content of each exemplar consisted of six feature values and additional background information. The feature values were generated from Binary-valued stımulus dimensions, three of which were predictive of category membership. The other three dimensions and the background information were irrelevant to category membership. Category membership was determined by an additive feature rule: if at least two of the three critical features were characteristic of exemplars given loans, then the loan was approved; otherwise, the loan was rejected.

The dimensions predictive of category membership were industry experience, the amount of the loan requested, and entrepreneurial motivation. Prior experience in running the same type of business, a loan size of between $\$ 75,000$ and $\$ 100,000$ rather than of between $\$ 600,000$ and $\$ 680,000$, and high entrepreneurial motivation (defined as seekıng challenge, setting personal goals, preparedness to take risks, or to be innovative, decisive, or selfmotivated) were predictive of loan approval. Each individual critical stimulus dimension predicted category membership on $75 \%$ of occasions. Loan size was the categorically relevant dimension which was varied to create the Good and Bad analogies. Categorically irrelevant dimensions were the suburb in which the person wished to establish the business (affluent or working class), alternate sources of finance (private investment or bank loan), and gender. Background information consisted of business type (clothes retailer, news agency, grocery shop, cafe) and slides of the faces of the purported loan applicants.

Each training item had one matching analogous test item, which could be either a Good or a Bad analogy. Although the abstract structure of the analogous items was identical on all but the dimension of loan size, the surface features of the analogous items were varied to ensure that the matching applicants were obviously independent people, although similar. Two training exemplars and their analogous test items are shown in Table 1. The faces that were parred with analogous items were matched on the basis of sex, estimated age, and overall appearance. Each matching exemplar pair was paired with a pair of faces, resulting in each exemplar having two potential faces. The assignment of face pairs to exemplar pairs was standard across subjects, but the specific face that subjects saw paired with each exemplar was randomized across experimental groups.
Table 1

Sample Training Items and Good and Bad Analogies

\section{Training Item A 1 (loan approved)}

Peter Smith wanted to establish a menswear retail store in Mt. Druitt. Peter wanted $\$ 95,000$. Unable to attract significant private investment, a loan from the Commonwealth Bank was Peter's other major source of finance. Peter had extensive experience in running menswear shops, tending to adopt a radical, aggressive and innovative approach in order to improve the business performance.

\section{Matching test item (Good analogy, loan approved)}

James Reynolds wanted to establish a menswear store in Blacktown. James wanted $\$ 660,000$. In the absence of significant investment, a loan from the State Bank was James' major alternate source of finance. James had been the manager of two menswear stores previously. He relished the challenge of trying to improve a business' performance by introducing new strategies and innovations to turn the business around.

\section{Training Item A4 (loan approved)}

Susan Hannon applied for an $\$ 88,000$ loan to establish a grocery shop in Marrickville. She had secured investment from a number of diverse sources, both within the industry, and from other sectors. Susan had managed a grocery shop for several years. As manager, Susan was conservative, avoiding the uncertainty associated with change.

\section{Matching test item (Bad analogy, loan rejected)}

Katrina Fulton applied for a $\$ 650,000$ loan to establish a grocery shop at Redfern. She had secured investment from several companies, including a prominent retail franchising operation. Katrina had been the manager of a grocery shop for the past four years. As a manager, Katrina was concerned to maintain continuity and stability of business practice.

Slides of faces and idiosyncratic feature values were used in an attempt to provide a rich and distinctive encoding context, mimicking real-world loan-decision situations in which impression formation and stereotyping occur. For example, in relation to the dimension "suburb," specific suburbs of Sydney commonly stereotyped as affluent or working class were used rather than the abstract descriptors. Similarly, to describe high entrepreneurial motivation, adjectives such as "decisive," "innovative," and "self-motivated" were used in different combinations for each exemplar.

Procedure. The subjects were tested in groups of up to 6 at a time. The stimuli were presented by means of an audio tape and slide projector, and the subjects were given questionnaires for recording their responses.

Subjects in the Rule group were informed that the study was designed to investigate how loan officers applied rules to make loan decisions. They were told the rule, and were instructed to use it to decide which applicants were given loans. Subjects in the Exemplar group were told that the study was designed to investigate how loan officers' memory for previous cases influenced their decisions, that they should attempt to memorize each exemplar, and that they would be given a test of memory after all the exemplars had been presented. Subjects in the Incidental group were told that the study was designed to investigate how impression formation influenced loans officers' decisions and that they were to make ratings based on their impressions of each of the loan applicants. The Exemplar and Incidental groups were not given the rule.

Following the instructions, the subjects were presented with the training stimulı. For each exemplar, first a face was projected onto the screen and then a recorded verbal description of the applicant was presented. After completion of the description of the applicant, the slide remained present and the subjects were required to rate the honesty of the applicant and the likelihood that he she would have been given the loan. The experimenter then asked the 
subjects to recall one of the six feature values comprising the exemplar (including business type and excluding gender). Twothirds of the questions required the recall of categorically irrelevant features, while the remaining one-third of the questions required the recall of categorically relevant features. The subjects were instructed to provide all answers as quickly as possible. Following completion of the recall question, the subjects were told whether or not the applicant had been given a loan. Slide offset followed the feedback, and then the next exemplar was presented.

The training phase consisted of 24 trials made up of eight exemplars, each repeated three times. The eight exemplars were presented in three consecutive blocks, with no exemplars repeated within any block. Randomizatıon of trial-presentation order within the blocks across subjects could not be achieved due to technological limitations, so the presentation order within blocks was standardized and the presentation order of blocks was counterbalanced instead. Two blocks ( 1 and 2 ) had different orders of exemplar presentation, which had been determined randomly, with the constraint that no more than three exemplars from the same category could occur consecutively. The third block was a repetition of one of the other two. The order of presentation of the blocks (1-2-1, 2-1-2) was counterbalanced across groups.

Upon completion of the training phase, the test phase was presented. The subjects were first given the categorization task. A face was projected onto the screen, the verbal description was presented, and the subjects were required to indicate whether they thought that each applicant would have been given a loan by the finance company. No feedback was given for categorization accuracy. Sixteen test exemplars were presented, consisting of the eight Old items, the four Good analogies, and the four Bad analogies. All subjects were presented with the same randomized order of test exemplars. The randomization constraints were the same as those followed for the trainıng stimuli, with the additional constraint that analogous item pairs be separated by at least two exemplars. Following the categorization test phase, the cued-recall task was administered. Two randomly chosen Old exemplars were used for the cued-recall task. The face associated with the first exemplar was presented, and the subjects were asked to recall the feature values of the exemplar. The face remained on the screen until all subjects had indicated that they had reported all they could remember or until $2 \mathrm{~min}$ had elapsed. A second randomly chosen exemplar was then presented in the same manner. The format of the cued-recall task was that of an open-ended questionnaire with headings for the three categorically relevant and the two categorically irrelevant stimulus dimensions (excluding gender) and one form of background information (business type). Following cued recall, the subjects were given a test of declarative knowledge of the categorization rule. The declarative knowledge test consisted of two open-ended questions. The first question asked what the categorization rule was, and the second question asked how they had made their categorization decisions. The cued-recall measure was scored in terms of the proportion of stimulus dimensions correctly recalled, averaged across the two exemplars. The declarative knowledge measure was scored in terms of the proportion of different critical stimulus dimensions mentioned in response to both questions.

\section{Results}

Categorization. The measure of categorization performance was the proportion of correct $(\mathrm{Pc})$ categorization responses to each type of item. Categorization performance is shown in Table 2. Planned analyses of categorization data were carried out within a $3 \times(3)$ multivariate model, repeated measures analysis of variance (ANOVA), using a decisionwise error rate with the criterion set at .05 .
Table 2

Proportion and Standard Error of Old Items, Good Analogies, and Bad Analogies Correctly Categorized in Experiment 1

\begin{tabular}{|c|c|c|c|c|c|c|}
\hline & \multicolumn{2}{|c|}{ Incidental } & \multicolumn{2}{|c|}{ Exemplar } & \multicolumn{2}{|c|}{ Rule } \\
\hline & $M$ & $\sigma_{\mathrm{M}}$ & $M$ & $\sigma_{\mathrm{M}}$ & $M$ & $\sigma_{\mathrm{M}}$ \\
\hline Old & .84 & .03 & .83 & .04 & .83 & .05 \\
\hline Good & .83 & .06 & .85 & .04 & .85 & .06 \\
\hline Bad & .46 & .06 & .46 & .08 & .63 & .08 \\
\hline
\end{tabular}

As predicted, the proportion of correct responses for Bad analogies was significantly less than the average of that for Good analogies and Old items $[F(1,34)=$ $\left.45.502, M S_{\mathrm{e}}=0.056, p<.001\right]$. There were no significant differences between the performance of the Incidental, Exemplar, and Rule groups, either as main effects or by interaction with analogy type. Post hoc $t$ tests revealed that the percentage of correct responses for all groups on the Bad analogies did not differ from chance.

To test the possibility that subjects were using criterial rules to classify stimuli, the pattern of individual subjects' responses was compared with the pattern of data expected if a criterial rule had been used. Kemler Nelson (1984) classified subjects as criterial rule users if, in a test phase requiring 12 categorization responses, more than 10 responses were consistent with the use of a single feature as a criterial rule. There were 16 test-phase decisions in the current study, so the subjects were classified as criterial responders if the number of responses consistent with the use of a single feature as a rule was greater than 13. One subject was classified as using experience as a criterial rule, and two were classified as using entrepreneurial motivation as a criterial rule. The analysis of categorization data was rerun with the criterial responders deleted from the analysis, and the difference between Bad analogy and the average of Goodanalogy and Old-item categorization (mean Bad analogy $\mathrm{Pc}=0.51$, mean Good/Old Pc $=0.83$ ) remained significant.

Declarative knowledge and cued recall. Table 3 shows the performance of the three groups on the declarative knowledge and cued-recall measures, and the correlations between performance on these measures and Old-item, Good-analogy, and Bad-analogy categorization performance. The Rule group performed significantly better than the Incidental and Exemplar groups on the declarative knowledge measure, identifying a greater proportion of critical features as being predictive of categorical membership $\left[F(1,34)=10.431, M S_{\mathrm{e}}=\right.$ $0.057, p<.01]$. The Exemplar group recalled marginally more features than the Incidental and Rule groups on the cued-recall test $\left[F(1,34)=3.786, M S_{\mathrm{e}}=0.047, p<.1\right]$.

There is a different pattern of correlations between the dependent measures for the Rule and Nonrule groups. In the Rule group, categorization accuracy for the Old items and Good analogies is highly correlated with performance on the declarative knowledge and cued-recall measures. However, performance on Bad analogies does 
Table 3

Means and Standard Error for Declarative Knowledge and Recall, and Correlations With Classification Accuracy, Across the Incidental, Exemplar, and Rule Groups

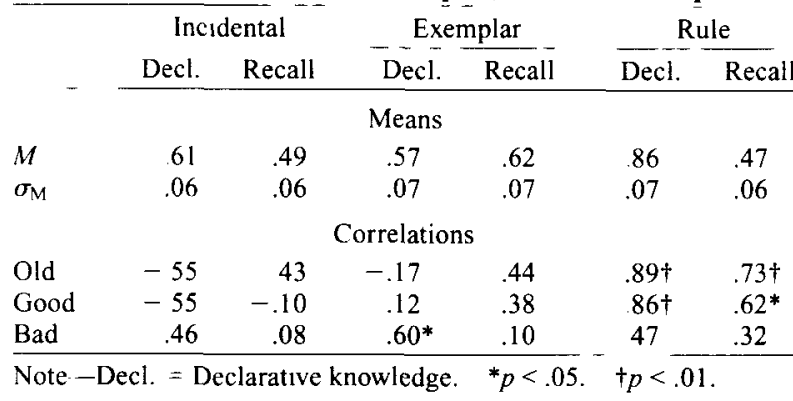

not correlate significantly with declarative knowledge or cued recall in the Rule group. Categorization performance generally does not correlate significantly with declarative knowledge and recall performance in the Nonrule groups. The correlation between Bad analogy categorization and declarative knowledge in the Exemplar group is the only significant correlation in the Nonrule groups. To test the significance of the observed differences in correlations between the three groups, the correlations were transformed to Fisher's $z^{\prime}$ values and the differences between scores in the groups were calculated in standard deviation units (Cohen \& Cohen, 1983 , p. 54). The correlations between Old item categorization and declarative knowledge are significantly greater in the Rule group than in the Exemplar and Incidental groups $\left(z^{\prime}=3.469, p<.001 ; z^{\prime}=4.327, p<\right.$ .0001 , respectively). The correlations between Good analogy categorization and declarative knowledge are also significantly greater in the Rule group than in the Exemplar and Incidental groups $\left(z^{\prime}=2.551, p<.001\right.$, and $z^{\prime}=4.054, p<.0001$, respectively). The correlation between Good analogy categorization and recall is greater in the Rule group than in the Incidental group $\left(z^{\prime}=1.750, p<.05\right)$. All other differences are nonsignificant (all $p \mathrm{~s}>.05$ ).

\section{Discussion}

The impairment of performance on the Bad analogies in both the Rule and Nonrule groups indicates that the similarity of the new test items to the training items influenced categorization. The critical characteristic of the $\mathrm{Bad}$ analogies that is assumed to be responsible for the poor performance on these items is their similarity to items in the opposite category. This similarity influenced categorization even for subjects in the Rule group, who had been given practice in using a simple and perfectly predictive rule to make their decisions. Such findings are difficult to reconcile with views of categorization which emphasize the importance of abstract knowledge at the expense of instance knowledge (see Allen \& Brooks, 1991).
The strength of the similarity effect in the current study is impressive, given the nature of the stimuli that were used. There was considerable potential for individual differences in judgments regarding which Old item matched any given new test item, because the features of each item were idiosyncratic. In addition, the major features of the stimuli were presented verbally and sequentially. Previous studies that used sequential information presentation in the form of feature lists (Allen \& Brooks, 1991, Experiment 2) have reported the elimination of instance effects. The difference between the current study and previous studies using sequential information presentation is that idiosyncratic feature values and visual cues, in the form of the faces, were used to provide a rich and distinctive encoding context in the current study.

The absence of differences in categorization accuracy between the Incidental and Exemplar groups suggests that learning is possible under "true" incidental instructional conditions, which make no reference to the need to abstract rules or memorize items. The absence of differences between the Incidental and Exemplar groups in the strength of correlations between categorization and declarative knowledge and cued recall further suggests that these two groups used the same strategies for categorization. It could be argued, however, that the instructional manipulation was relatively weak because the three groups had to answer the same questions during training. The questions may have led subjects to encode information that was unrelated to the stated instructions. For example, the recall question may have forced the Incidental group to intentionally memorize the items. Experiment 2 uses a modified incidental learning task to more tightly constrain processing strategies during training.

The categorization data in isolation are not fully revealing about the nature of the mechanisms underlying categorization decisions. The correlational data imply, first, that there are differences in the nature of categorization of Good and Bad analogies in the Rule group, and second, that there are differences in the nature of categorization in the Rule and Nonrule groups despite the absence of differences in the accuracy of categorization in the two groups. In the Rule group, for all but Bad analogies, categorization accuracy was related to declarative knowledge and cued recall, both of which are direct, explicit tests of analytic knowledge. Categorization in the Rule group, therefore, was apparently analytic when instance and rule knowledge predicted the same response. When the response predicted by instance knowledge was the opposite of that predicted by rule knowledge (Bad analogies), then categorization was no longer analytic. In the Nonrule groups, categorization accuracy tended not to intercorrelate with declarative knowledge or cued recall, suggesting that performance in the Nonrule groups was generally not analytic in nature. 
The only significant Nonrule correlation was between Bad analogy categorization and declarative knowledge in the Exemplar group. It is difficult to explain why categorization accuracy in the Exemplar group should be related to rule knowledge for Bad analogies but not for the Old items and Good analogies when this effect is reversed in the Rule group. It may be that, since the responses predicted by similarity and the rule converge for Old items and Good analogies, subjects do not need to rely on the rule for these items. For Bad analogies, however, the responses are in conflict. The subjects who know the rule may be more likely to favor its use when the responses predicted by similarity and the rule are in conflict.

The problem with the correlational approach, however, is that it does not allow inferences to be drawn regarding the nature of the processes involved when the correlations between the measures are not significant. Categorization and cued recall were essentially unrelated for Rule-group Bad analogies and for Nonrule group items in general, suggesting that the influence of similarity was not related to the explicit retrieval of specific individual features in these conditions. These data, however, do not allow any more specific inferences to be drawn regarding whether retrieval is conscious or automatic. This highlights the more general problem of attempting to draw inferences regarding the nature of processes on the basis of patterns of association and dissociation between tasks. To infer the relative contributions of conscious recollection and automatic retrieval, in addition to rule use, Experiment 2 employed the process dissociation methodology (Jacoby, 1991). Process dissociation methodology is designed to infer the relative contribution of two independent processes to an outcome measure, such as recognition judgments. Unlike approaches that rely on finding associations or dissociations between tasks, the process dissociation procedure does not require the assumption that particular tasks represent pure measures of specific processes. Process dissociation is a more appropriate procedure than the procedures used in Experiment 1, given the assumption that both automatic and intentional processes should influence categorization.

\section{EXPERIMENT 2}

The logic of process dissociation is that the relative contribution of independent intentional and automatic processes can be estimated by comparing performance in a condition when the processes act together with a condition in which they act in opposition. Intentional processes, by definition, are sensitive to intentional control, and so should be affected by instructions informing subjects to change their responses to specific stimuli. Automatic processes are not sensitive to intentional control, and so should not be affected by such instructions. The instructions informing subjects to change their responses are termed exclusion instructions. Because intentional processes are sensitive to the exclusion instructions but automatic processes are not, the exclusion instructions serve to place intentional responding in opposition to automatic responding.

Jacoby et al.s' (1989) "false fame" studies illustrate how intentional responding can be placed in opposition to automatic responding. In the false-fame paradigm, subjects are presented with a study list of nonfamous names, followed by a test phase in which they are told to identify which names are famous. The test list consists of both names from the study list and new items. Intentional and automatic processes are placed in opposition by informing subjects that all the names from the original list are nonfamous. If subjects can consciously recollect a name from the study list, then they should be able to reject the item. If the item is retrieved automatically, but not recollected, then subjects should mistakenly accept the item as famous. That is, automatic forms of retrieval can be indexed by false alarms to the study items. Such false alarms cannot be caused by recollection of the instances, because conscious recollection would allow the subject to exclude the item.

In the present study, the exclusion instructions informed subjects that they should reject loans for specific items which they had been told were approved in the training phase. If responding is based on information that is exclusively under intentional control, then the loans for these key items should be rejected. If responding is based on a source of information that is retrieved automatically, then loans for these key items should be approved, despite instruction to the contrary.

The process-dissociation procedure has been generalized in Experiment 2 to allow for the estimation of three processes, rather than two, across different learning conditions and analogy types. The intentional processes that are assumed to influence categorization are rule use and conscious recollection of a study instance. The process that is assumed not to be subject to intentional control is automatic responding based on similarity to previous training instances (termed automatic retrieval). To estimate the contribution of the three processes, dependent measures representing unique combinations of these three processes are required from three separate conditions. Performance needs to be measured in (1) an Inclusion condition, in which all three processes predict approval of loans for the key items, (2) an Exclusion condition in which subjects attempt to use conscious recollection of analogous items to identify the specific items for which they should reject loans, and (3) an $E x$ clusion condition in which subjects attempt to use the rule to identify the specific items for which they should reject loans.

To implement the process-dissociation technique, a third category was added to the category structure used in Experiment 1. The category given loans in Experiment 1 was labeled as sound investments, and the category not given loans in Experiment 1 was labeled as average investments; the new category was labeled poor 


$\begin{array}{lllll}\text { Table 4 } & \text { Predicted Effects of the Memory-Exclusion and } \\ \text { Rule-Exclusion Instructions on Classification } \\ \text { of Sound and Average Investments }\end{array}$

investments. The poor investments are not relevant to any of the predictions, and so are not considered any further. As in Experiment 1, Good and Bad analogies were created for each training item by changing one critical feature. The feature change caused the Bad analogies to fall into the category opposite that of the Old item that they resembled. Specifically, the Bad analogies that resembled sound investments were average investments, and those that resembled average investments were sound investments.

The Exclusion instructions identified the average investments as the key items to be rejected. In the training phase, subjects were told that both sound and average investments were given loans. Subsequently, Exclusion instructions informed the subjects that average investments were no longer to be given loans. Depending on the Exclusion group that they were in, the subjects were instructed either to use recollection to identify the average investments and to reject their loans or to use the rule to identify the average investments and to reject their loans.

The logic of the Exclusion conditions is summarized in Table 4. The Memory-Exclusion condition was designed to bring recollection under instructional control. Subjects were told that if they could recollect the most similar case from the training phase and remember that it was an average investment, then they should reject the loan. In cases in which they could not remember the analogous item and/or its investment rating, the subjects were instructed to respond as they had in the training phase, when both sound and average investments were given loans. If subjects in the Memory-Exclusion group can recollect the relevant training items, they should approve loans to Old items and Good analogies that are sound investments but reject loans for Old items and Good analogies that are average investments. Since the Bad analogies fall into a category opposite to that of the Old item that they resemble, subjects should reject loans for Bad analogies that are sound investments and approve loans for Bad analogies that are average investments.

The Rule-Exclusion condition was designed to bring rule use under instructional control. Subjects were told that the criteria for giving loans had changed, and that average investments were no longer to be given loans. The subjects were alerted to the existence of the Bad analogies, and were informed that they should use the rule to avoid making errors on these items. If subjects in the Rule-Exclusion group were able to use the rule, then they should not be misled by the Bad analogies and should approve loans to all sound investments and reject loans for all average investments (see Table 4).

To simplify the presentation of the results, the categorization data is presented in terms of difference scores between the approval rate for sound investments and that for average investments. The difference in approval rate between sound and average investments is a measure of the effectiveness of the Exclusion manipulations. If categorization responses are sensitive to intentional control, then the difference in approval rate between sound and average investments should be greater in the Exclusion groups than in the Inclusion group, because both Exclusion groups were told to reject average investments. If similarity to training instances influences categorization, then this interaction between investment type and the Inclusion/Exclusion condition should be stronger for Old items and Good analogies than for Bad analogies, because the Bad analogies are similar to the training items from the opposite category. If similarity effects in categorization are due to conscious recollection, then the interaction between investment type and analogy type should be evident in the MemoryExclusion group, where subjects are explicitly instructed to use recollection of similar training items to exclude the average investments. If there is also an automatic component to similarity effects, then the interaction between investment type and analogy type should also hold in the Rule-Exclusion group, where subjects were instructed to use the rule to exclude the average investments. Any influence of similarity on performance in the Rule-Exclusion condition should be involuntary, because the Rule-Exclusion group was alerted to the existence of the Bad analogies and should have been able to avoid making errors on these items.

If rule use influences categorization, then the difference in approval rates between sound and average investments should be greater in the Rule-Exclusion group than in the Memory-Exclusion group, because rule use predicts approval of average investments in the MemoryExclusion group but rejection in the Rule-Exclusion group.

These different bases for categorization might interact with encoding condition. The Rule encoding task requires subjects to analytically apply a rule, while the Incidental encoding task requires subjects to integrate the featural information (to form a global impression). Naturally, the Rule group would be expected to use the rule to a greater extent than the Incidental group. The Incidental group, on the other hand, might be expected to use recollection to a greater extent than the Rule group, because the Incidental encoding task should produce a more elaborate or distinctive memory trace than the Rule encoding task. The Rule group should therefore be able to implement the Rule-Exclusion instructions more effectively than the Incidental group, while the Incidental group may implement the Memory-Exclusion instructions more effectively than the Rule group. 
The preceding hypotheses concerning the contribution of different processes to categorization are expressed in terms of proportions of "approve" judgments to different categories of exemplar. It is also possible to derive estimates of the different processes using process dissociation. The process-dissociation procedure requires models of the influence of rule application $(\mathrm{Ru})$, recollection ( $\mathrm{Re})$, and automatic retrieval (A) on the dependent measure in the Inclusion, Memory-Exclusion, and Rule-Exclusion groups to be expressed as a set of simultaneous equations. The equations can then be solved to produce estimates for the three processes as a function of the measured variables. Each estimate $(\mathrm{Ru}, \mathrm{Re}, \mathrm{A})$ represents the probability of responding on the basis of that process. The terms A.Ru, A.Re, Ru.Re, and A.Ru.Re represent the products of each of the three estimates. In set theoretic terms, the products represent the intersections of the three sets $(\mathrm{Ru}, \mathrm{Re}$, and $\mathrm{A})$. The equations modeling the influence of the Inclusion and Exclusion instructions on the three processes for Old items, Good analogies, and Bad analogies are presented below. The solutions to the equations are given in Appendix B.

The Inclusion instructions requested subjects to classify exemplars in the same manner as in the training phase. As average investments were given loans in the training phase, the three processes all predict approval of loans for average investments. The probability of approving loans for all types of average investments (Old items, Good analogies, and Bad analogies) in the Inclusion group $\left(I_{A}\right)$ is, therefore, the sum of the independent probabilities of responding on the basis of each of the three processes:

$$
\begin{aligned}
I_{A}= & A+R u+R e \\
& -(A \cdot R u+A \cdot R e+R u \cdot R e-A \cdot R u \cdot R e) .
\end{aligned}
$$

The Memory-Exclusion instructions place recollection in opposition to automatic retrieval and rule use. For Old items and Good analogies, recollection of the relevant training item predicts rejection for average investments. Automatic retrieval and rule application, on the other hand, predict approval of loans to average investments as these processes should not be influenced by the Memory-Exclusion instructions. For Good analogies and Old items, the probability of approving loans to average investments under Memory-Exclusion instructions $\left(\mathrm{M}_{\mathrm{A}}\right)$ is the sum of the independent probabilities of responding on the basis of automatic retrieval and the rule when the items cannot be recollected:

$$
\begin{aligned}
\mathrm{M}_{\mathrm{A}}= & \mathrm{A}+\mathrm{Ru} \\
& -(\mathrm{A} \cdot \mathrm{Ru}+\mathrm{A} \cdot \mathrm{Re}+\mathrm{Ru} \cdot \mathrm{Re}-\mathrm{A} \cdot \mathrm{Ru} \cdot \mathrm{Re}) .
\end{aligned}
$$

When dealing with Bad analogies, the MemoryExclusion instructions place recollection in opposition to automatic retrieval and rule use for sound investments rather than average investments. While recollection predicts rejection for Bad analogy/sound investments, automatic retrieval and rule use predict approval. For Bad analogies, the probability of approving loans to sound investments under Memory-Exclusion instructions $\left(\mathrm{M}_{\mathbf{S}}\right)$ is the sum of the independent probabilities of responding on the basis of automatic retrieval and the rule when the items cannot be recollected:

$$
\begin{aligned}
M_{S}= & A+R u \\
& -(A \cdot R u+A \cdot R e+R u \cdot R e-A \cdot R u \cdot R e) .
\end{aligned}
$$

The Rule-Exclusion instructions place rule use and recollection in opposition to automatic retrieval for Old items and Good analogies. For Old items and Good analogies, both rule use and recollection can be used to identify an instance as an average investment and to reject the loan. Only automatic retrieval is assumed to result in approval for Old items and Good analogies. For Old items and Good analogies, the probability of approving loans to average investments in the RuleExclusion condition $\left(R_{A}\right)$ is the probability of responding on the basis of automatic retrieval when the rule is not applied and the instance is not recollected:

$$
R_{A}=A-(A \cdot R u+A \cdot R e-A \cdot R u \cdot R e) .
$$

When dealing with Bad analogies, the Rule-Exclusion instructions place rule use in opposition to both automatic retrieval and recollection. While rule use predicts rejection for Bad analogy/average investments, both automatic retrieval and recollection predict approval. For $\mathrm{Bad}$ analogies, the probability of approving loans to average investments in the Rule-Exclusion condition $\left(R_{A}\right)$ is the sum of the independent probabilities of responding on the basis of automatic retrieval and recollection when the rule is not applied:

$$
\begin{aligned}
R_{A}= & A+R e \\
& -(A \cdot R u+A \cdot R e+R e \cdot R u-A \cdot R u \cdot R e) .
\end{aligned}
$$

\section{Method}

Design. A $2 \times 3 \times(3 \times 3)$ design was used. The first betweengroups factor was the encoding instructions given to subjects, who learned under either Incidental or Rule conditions. Unlike in Experiment 1, an Exemplar group was not included. The second between-groups factor was the instructions, termed retrieval instructions, designed to independently manipulate the influence of the three processes on categorization decisions. The three retrieval groups were the Inclusion, Memory-Exclusion, and RuleExclusion groups. The within-group factors were analogy type (Old, Good, Bad) and investment category (sound, average, poor).

Subjects. Sixty-eight undergraduate students participated as part of a class practical. There were 44 females, 18 males, and 6 subjects for whom gender was not recorded.

Stimuli and Materials. The stimuli were adapted from those used in Experiment 1. There were three categories of loan applicants, with four training items in each category. As in Experiment 1 , category membership was determined by an additive feature rule-if at least two of the three critical features were characteristic of a particular category (sound, average, or poor investments), then the exemplar was a member of that category. The features that were characteristic of sound investments were experience in running the same type of business, an application for less than $\$ 100,000$, and high ent repreneurial motivation (e.g., aggres- 
sive, innovative, or self-motivated). The features that were characteristic of average investments were experience in running a different type of business, an application for between $\$ 500,000$ and $\$ 600,000$, and moderate entrepreneurial motivation (e.g., cautious, prudent, or dependable). The features that were characteristic of poor investments were no prior experience in businesses, an application for over $\$ 900,000$, and low entrepreneurial motivation (e.g., unmotivated, lack of enthusiasm, or extreme caution). Two analogies were generated for every sound and average investment training item. As in Experiment 1, loan size was the categorically relevant dimension varied to create the first set of analogies. Entrepreneurial motivation was the categorically relevant dimension varied to create the second set of analogies. Half of the analogies were Good and half were Bad. One analogy was created for each poor investment training item by varying the categorically irrelevant other-finance dimension. None of the analogies of poor investments switched category. The addition of both the extra category and analogies resulted in 32 test items (see Appendix A).

Procedure. The procedure for the training phase was similar to that of Experiment 1. The Rule group was given the rule and told to use it to decide which applicants were to be given the loans; the Incidental group was not given the rule, and was told that they should make ratings on the basis of their impressions. Some changes were made to the Incidental and Rule training tasks to strengthen the distinction between the two groups by encouraging holistic encodings in the Incidental task and analytic encodings in the Rule task. Neither group was asked to recall feature values after classifying the exemplars. Both groups had to rate whether the applicant would have been given a loan and to indicate whether the applicant represented a sound, average, or poor investment. The Incidental group was additionally asked to rate the extent to which their overall, global impression of the applicant was positive and to indicate whether or not they thought that the applicant was honest. The Rule group was not asked any additional questions. Three blocks of the 12 training items were presented consecutively. The first block was divided into three sub-blocks in which all four average investments were presented consecutively withın the first sub-block, followed by all sound investments in the second and all poor investments in the third. Upon completion of each sub-block, the experimenter alerted subjects to the fact that all items in that sub-block had the same investment rating and were all either granted or refused a loan. The structuring of the first block of items was designed to ensure that subjects were explicitly aware of the relationship between investment rating (sound, average, poor) and of whether loans were approved or rejected. The order of presentation within each sub-block was determıned randomly prior to the experiment, with all subjects receiving the same presentation order. Blocks 2 and 3 were not divided into sub-blocks. The pseudorandom order of presentation within Blocks 2 and 3 was the same as that followed in Experiment 1 . Due to constraints imposed by running subjects in groups, there was no counterbalancing of order of presentation. All subjects received the same order of presentation of stimuli. Following the training phase and prior to the test phase, the subjects were presented with the Inclusion, Memory-Exclusion, or Rule-Exclusion instructions. Following the presentation of the retrieval instructions, the test phase exemplars were presented.

\section{Results}

Analysis of variance. The subjects were highly successful in rejecting loans for the poor investments. The mean approval rate for poor investments was $.04(S D=$ $.08)$. Planned analyses of the data for sound and average investments were carried out within a $2 \times 3 \times(3 \times 2)$ multivariate model ANOVA, using a decisionwise error rate
Table 5

Proportion and Standard Error of Loans Approved to Each Category of Applicant in Experiment 2

\begin{tabular}{|c|c|c|c|c|c|c|c|c|c|}
\hline \multirow[b]{3}{*}{ Group } & \multirow{3}{*}{$\begin{array}{c}\text { Analogy } \\
\text { Type }\end{array}$} & \multicolumn{4}{|c|}{ Incıdental } & \multicolumn{4}{|c|}{ Rule } \\
\hline & & \multicolumn{2}{|c|}{ Sound } & \multicolumn{2}{|c|}{ Average } & \multicolumn{2}{|c|}{ Sound } & \multicolumn{2}{|c|}{ Average } \\
\hline & & $M$ & $\sigma_{\mathrm{M}}$ & $M$ & $\sigma_{\mathrm{M}}$ & $M$ & $\sigma_{\mathrm{M}}$ & $M$ & $\sigma_{\mathrm{M}}$ \\
\hline \multirow[t]{3}{*}{ Incl. } & Old & .95 & .03 & .84 & .0 & 1,00 & .00 & .93 & .03 \\
\hline & God & .93 & .05 & .77 & .07 & .98 & .02 & 82 & 07 \\
\hline & Bad & .73 & .09 & .75 & .06 & .89 & .07 & .82 & .07 \\
\hline \multirow[t]{3}{*}{ M-Ex } & Old & .81 & .06 & .40 & .09 & .91 & .04 & 65 & 09 \\
\hline & Good & .87 & .06 & .46 & .10 & .93 & .03 & .58 & .09 \\
\hline & $\mathrm{Bad}$ & .58 & .08 & .77 & .06 & .71 & .07 & 57 & .08 \\
\hline \multirow[t]{3}{*}{ R-Ex } & Old & .83 & .04 & .33 & .05 & .82 & .05 & .07 & .05 \\
\hline & Good & .73 & .05 & .29 & .06 & .91 & .05 & .21 & .09 \\
\hline & Bad & .63 & .08 & .46 & .06 & .71 & .06 & .32 & .07 \\
\hline
\end{tabular}

Note-Incl. = Inclusion group, M-Ex = Memory-Exclusion group, $\mathrm{R}-\mathrm{Ex}=$ Rule-Exclusion group.

with the criterion set at .05 . Post hoc tests used the Scheffé procedure with a Dunn adjustment to control for the number of repeat contrasts tested. Only contrasts reflecting differences between sound and average investments are reported. Table 5 shows the proportion of loans approved for sound and average investments across all experimental conditions. The differences between approval rates for sound and average investments, which are central to the predictions, are plotted in Figure 1. A positive difference score indicates that subjects were more likely to approve loans for sound investments than for average investments. A negative difference score indicates that subjects were more likely to approve loans for average investments than for sound investments.

Categorization responses were sensitive to the Exclusion instructions (both Memory and Rule) and analogy-

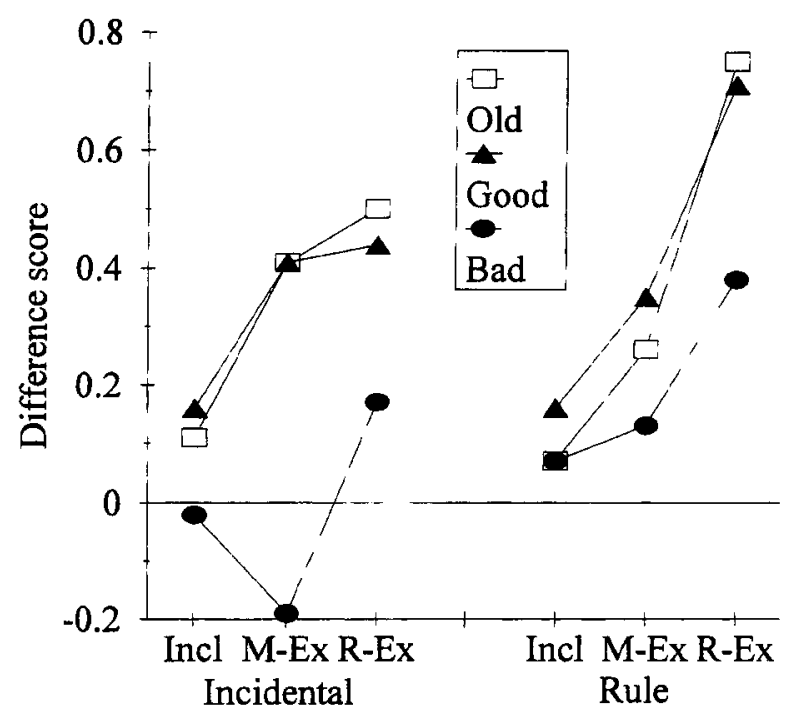

Figure 1. Differences in approval between sound and average investments (difference score) across the Inclusion (Incl), MemoryExclusion (M-Ex), and Rule-Exclusion (R-Ex) groups. 
type manipulations. As predicted, the effect of both the Memory- and Rule-Exclusion instructions on the probability of approving loans was to increase the difference in approval rates between sound and average investments. Across both the Incidental and Rule groups, the difference in approval rate between sound and average investments was greater for the average of the two Exclusion groups than for the Inclusion group $[F(1,62)=$ $\left.31.457, M S_{\mathrm{e}}=0.052, p<.01\right]$. However, this interaction between investment type and Inclusion/Exclusion conditions was stronger for Old items and Good analogies than for Bad analogies $\left[F(1,62)=6.396, M S_{\mathrm{e}}=0.049\right.$, $p<.05]$, indicating that similarity to previous training items influenced categorization. The interaction between investment type and analogy type was significant in both the Memory-Exclusion group $[F(1,21)=16.735$, $\left.M S_{\mathrm{e}}=0.069, p<.01\right]$ and the Rule-Exclusion group $\left[F(1,21)=17.417, M S_{\mathrm{e}}=0.045, p<.01\right]$, which suggests that there may have been both a voluntary and an involuntary component to the influence of similarity on categorization. Although the categorization responses were sensitive to both Exclusion instructions, the RuleExclusion instructions were applied more effectively than the Memory-Exclusion instructions. The difference in approval rate between sound and average investments was greater in the Rule-Exclusion groups than in the Memory-Exclusion groups $\left[F(1,62)=22.104, M S_{\mathrm{e}}=\right.$ $0.052, p<.01]$, which suggests that rule use also influenced categorization.

The encoding conditions influenced the interaction between investment type and analogy type in the Memory-Exclusion group but not in the Rule-Exclusion group. The interaction between investment type and analogy type in the Memory-Exclusion condition was stronger in the Incidental group than in the Rule group $\left[F(1,21)=5.263, M S_{\mathrm{e}}=0.069, p<.05\right]$. This interaction shows that the Incidental encoding group implemented the Memory-Exclusion instructions more accurately than did the Rule encoding group, and suggests that the effect of similarity under Memory-Exclusion conditions was influenced by the encoding tasks. For the Bad analogies, the subjects who successfully implement the Memory-Exclusion instructions should reject sound investments and approve average investments. The Incidental encoding group demonstrated this reversal in approval rates, but the Rule group did not. For the Old items and Good analogies, Memory-Exclusion subjects should approve sound investments and reject average investments. The difference between the approval rates for sound and average investments was greater for the Incidental/Memory-Exclusion group than for the Rule/ Memory-Exclusion group on Old items and Good analogies. Although the Rule group implemented the RuleExclusion instructions more accurately than did the Incidental group $\left[F(1,21)=7.296, M S_{\mathrm{e}}=0.071, p<.05\right]$, this interaction was not modified by analogy type $\left[F(1,21)=0.064, M S_{\mathrm{e}}=0.045, p>.05\right]$. That is, the difference between the approval rates of sound and av- erage investments was greater for the Rule/RuleExclusion group than for the Incidental/Rule-Exclusion group across all analogy types. This interaction suggests that, although the Rule encoding group used the rule to a greater extent than did the Incidental encoding group, the encoding conditions had no impact on the effect of similarity in the Rule-Exclusion groups. The differential effect of the encoding conditions on the interactions between investment type, analogy type, and Exclusion condition produced a significant four-way interaction $\left[F(1,62)=4.347, M S_{\mathrm{e}}=0.049, p<.05\right]$.

Process dissociation estimates. The process estimates, derived from entering the data in Table 5 into the process equations, are shown in Figure 2. The baseline values for the estimates of recollection and rule use are zero, while the baseline for automatic retrieval is $.5 .^{1}$ The process estimates are based on group averages and cannot be estimated for individual subjects, so it is not possible to derive direct measures of the variance of the estimates.

The estimates for rule use and recollection generally appear to be greater than chance. In particular, the estimates for rule use are clearly greater than chance in the Rule encoding group. The estimates for automatic retrieval, on the other hand, do not appear to differ substantially from chance. The estimate for the Old items in the Incidental encoding group is the only estimate that exceeds 6 .

Analogy type influenced the estimates for both rule use and recollection. The estimates for rule use within the Rule encoding group are substantially higher for the Old items than for the Good and Bad analogies. This is because the difference between the approval rates for average investments in the Memory- and Rule-Exclusion conditions, within the Rule encoding group, is greater for the Old items than for the Good and Bad analogies [post hoc test: $F_{05 i 1}(1,20)=7.721, M S_{\mathrm{e}}=0.034, p<.05$ ].

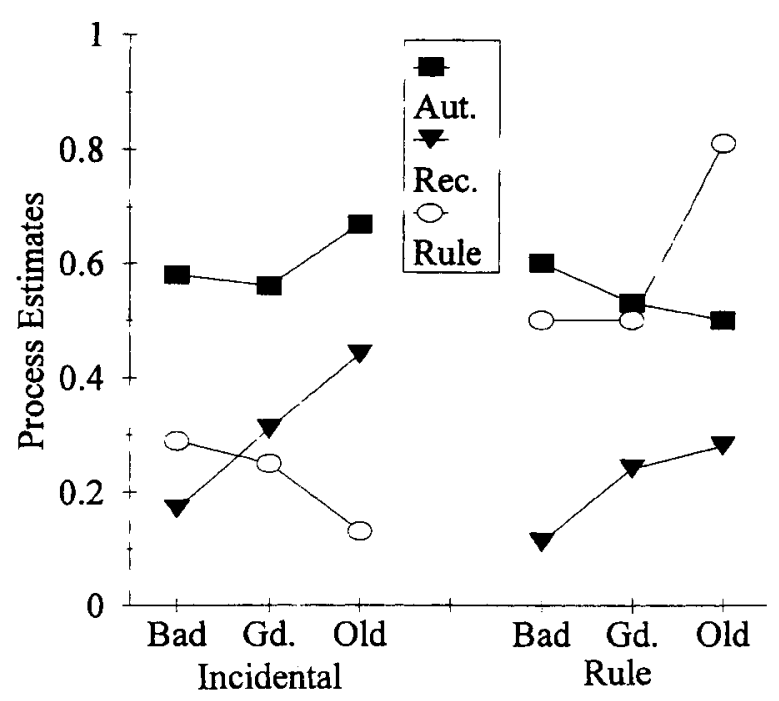

Figure 2. Process estimates. 
The estimates of recollection are lower for Bad analogies than for Old items and Good analogies, and may not be greater than chance. The recollection estimates are lower for the Bad analogies because the estimate for Bad analogy recollection makes use of the sound investments in the Memory-Exclusion condition rather than of the average investments. The approval rates for sound and average investments in the Memory-Exclusion conditions had to be fully reversed for the Bad analogies, by comparison with the Good analogies, if the estimates for recollection were to be equal for the Good and Bad analogies.

Further analyses. Subjects were classified as criterial rule responders if they made four or fewer responses discrepant from the pattern of responses predicted by the use of a single feature as a criterial rule. The criterion for classifying subjects is, in relative terms, equivalent to that used in Experiment 1, because double the number of test exemplars were used. Although 8 subjects met the criteria for categorization as criterial rule responders, 2 of those had performance patterns that matched the patterns predicted by the categorization rule, recollection, or automatic retrieval equally well. When the remaining 6 criterial responders were excluded from the analysis, the results from the ANOVA and process dissociation procedure were largely unchanged.

\section{Discussion}

The study aimed to disentangle, first, the effects of rule use from similarity, and second, the relative contribution of intentional and automatic forms of retrieval to similarity effects. The performance of the Rule-Exclusion groups by comparison with the Memory-Exclusion groups provides a measure of rule use. Rule use predicts approval of loans for average investments in the MemoryExclusion groups and rejection in the Rule-Exclusion groups. If subjects use the rule, then the difference in approval rates between sound and average investments should be greater for the Rule-Exclusion groups than for the Memory-Exclusion groups. As expected, the difference in approval rates for sound and average investments was larger in the Rule-Exclusion groups than in the Memory-Exclusion groups, indicating that rule use influenced categorization decisions.

The influence of similarity can be inferred by comparing the effectiveness of the Exclusion instructions on Good analogies and Old items with their effectiveness on Bad analogies. Recall that the Bad analogies resembled items in the opposite category, so that sound investments resembled average investments, and vice versa. If similarity influences responding, then the difference in approval rates between sound and average investments in both Exclusion groups should be smaller for the Bad analogies than for the Good analogies and Old items. This predicted consequence of similarity was evident in both Exclusion conditions.

The contribution of conscious recollection to similarity effects can be inferred by comparing the performance of the Memory-Exclusion groups with that of the Inclusion groups. The Memory-Exclusion groups were explicitly instructed to use recollection to exclude items that resembled the average investments that were presented in the training phase. The Memory-Exclusion groups approved fewer loans to items that resembled average investments than did the Inclusion groups, suggesting that recollection contributed to categorization performance. In particular, the Incidental' MemoryExclusion group actually approved more loans for Badanalogy average investments than for Bad-analogy sound investments, which strongly suggests that these subjects were able to use conscious recollection of similar instances to guide categorization decisions when explicitly instructed to do so.

Although the differences between the Inclusion and Memory-Exclusion conditions suggest that categorization decisions can be based on the voluntary recollection of training instances, the fact that similarity also influenced performance in the Rule-Exclusion group suggests that automatic retrieval processes may contribute to categorization. It is unlikely that the influence of similarity on performance in the Rule-Exclusion group could have been intentional, because the subjects were alerted to the existence of the $\mathrm{Bad}$ analogies, and were explicitly instructed to avoid making errors on these items. Even giving the subjects practice at using the rule could not eliminate the influence of similarity (cf. Allen \& Brooks, 1991).

In summary, then, the combination of Incidental encoding and Memory-Exclusion retrieval conditions produced the strongest influence of exemplar similarity, whereas the combination of Rule encoding and RuleExclusion retrieval conditions produced the strongest influence of rule use. The strength of the similarity and rule-use effects under these combinations of encoding and retrieval conditions is consistent with the principle of transfer appropriate processing (Morris, Bransford, \& Franks, 1977). The strongest evidence for recollective processes is in the Incidental/Memory-Exclusion group, where both the encoding and retrieval conditions favor reliance on memory for individual examples. The strongest evidence for reliance on rule use occurs in the Rule/Rule-Exclusion group, where both encoding and retrieval conditions require the application of rules.

A more fine-grained analysis of the data reveals that the encoding conditions appear to have exerted different effects on each of the processes contributing to categorization. The encoding tasks appear to have had opposite effects for rule use and recollection, and to have no effect on automatic uses of memory. Not surprisingly, the Rule encoding group was more effective in implementing the Rule-Exclusion instructions than was the Incidental encoding group, indicating that the group that was given the rule during training used it to a greater extent than did the group that was not given the rule. The influence of exemplar similarity on performance in the Exclusion conditions can be indexed by the differences 
in performance for Good and Bad analogies. While the effect of similarity in the Memory-Exclusion groups was stronger when subjects were given the Incidental encoding task than when they were given the Rule encoding task, the encoding conditions had no impact on the effect of similarity in the Rule-Exclusion groups. The influence of similarity on the performance of the MemoryExclusion groups should represent a combination of both intentional and automatic uses of memory, while the influence of similarity in the Rule-Exclusion groups should reflect only automatic uses of memory. The encoding tasks, therefore, do not appear to have had any impact on automatic uses of memory, since the differences between Rule-Exclusion performance for Good and Bad analogies were equally evident in both the Rule and Incidental encoding tasks. This finding is consistent with the assumption that automatic forms of retrieval remain invariant across encoding manipulations that affect depth of processing (such as divided attention; see Jacoby et al., 1993). By contrast, the effect of the encoding tasks on similarity effects in the Memory-Exclusion groups indicate the sensitivity of intentional uses of memory to encoding condition.

Process estimates. The process estimates for recollection and rule use are generally consistent with the results of the ANOVA. The process estimates suggest that rule use was stronger in the Rule encoding group, and that recollection was stronger in the Incidental encoding group. An interesting finding, which is not apparent from the ANOVA, is that the estimate for rule use is greater for the Old items than for the Good and Bad analogies in the Rule group. The estimate for Old items in the Rule encoding group is higher than that for the Good and Bad analogies, because the effect of the RuleExclusion instructions on the approval rate for average investments was greater for the Old items than for the Good and Bad analogies. This finding does not appear to be consistent with traditional approaches to skill acquisition (Anderson, 1983; Shiffrin \& Schneider, 1977). The experience of having applied the rule to classify a particular item appears to have facilitated subsequent use of the rule on that item. The effect of experience could not have simply been to strengthen the rule, as traditional approaches to skill acquisition would suggest, because the effect of experience appears to have been specific to previously encountered items.

Although the estimates for Old-item and Goodanalogy recollection converge with the findings from the standard ANOVA, the estimates for Bad-analogy recollection do not. Performance on Bad analogies under Memory-Exclusion conditions provided relatively strong evidence of recollection of training items, particularly in the Incidental group. By contrast, the estimates of recollection are lower for Bad analogies than for Old items and Good analogies. The estimates for Bad analogies appear anomalous, and most likely reflect differences in the process estimation procedure for Good and Bad analogies. The estimates for Bad analogies rely on a different set of process estimates derived from performance on sound rather than average investments. The process estimates are not, therefore, directly comparable to those for Old items and Good analogies.

The estimates of the influence of automatic retrieval processes provide little evidence that such retrieval influences categorization, because none of the estimates differ markedly from a chance value of .5. These data appear to contradict the conclusion drawn from consideration of the differences between performance for Good and Bad analogies in Rule-Exclusion conditions, which were interpreted as demonstrating the influence of automatic retrieval of the instances from which the Bad analogies were created.

The differences in interpretations regarding recollection of Bad analogies and automatic influences of memory probably reflect limitations in the process-estimation procedure. The process-estimation procedure requires the assumption that the three processes ( $A, R e, R u)$ are independent of each other. The finding that estimated rule use was greater for Old items than for Good analogies suggests that rule use may not be independent of memory for instances. Another assumption underlying the process estimates is that the Exclusion instructions should not produce a shift in subjects' decision criteria. The Exclusion instructions should have influenced the approval rate for average investments alone and should not have influenced the approval rate for sound investments (for Old items and Good analogies). However, the approval rate for sound investments was lower in both of the Exclusion conditions than in the Inclusion condition. This suggests that the decision criteria used by the Exclusion groups were different from the decision criteria used by the Inclusion groups. By not taking into account this criterion shift, the process estimates may have overestimated the contribution of recollection and rule use and underestimated the contribution of automatic retrieval.

The difficulties in assessing the contribution of automatic retrieval processes arise because the encoding tasks were designed to directly manipulate rule use and recollection, but not automatic retrieval. Like a number of the studies that have used the process-dissociation technique (Begg, Anas, \& Farinacci, 1992; Jacoby, 1991; Jennings \& Jacoby, 1993), the current study can demonstrate only a one-way dissociation between automatic and intentional processes. To implicate the existence of two processes, however, it is necessary to at least demonstrate that a variable that has an effect on one process can have the opposite effect on the other process; that is, it is necessary to produce a double dissociation (Dunn \& Kirsner, 1988; see Jacoby et al., 1993, for an example using process dissociation). In the context of the current experiment, the absence of a variable designed to manipulate the strength of automatic influences of memory makes the apparent failure of the process estimates to reliably exceed chance levels difficult to interpret. Techniques for testing for the existence of double dissocia- 
tions between automatic retrieval and recollection in a categorization paradigm are currently under development in our laboratory.

A further problem is that the validity of the conclusions drawn from the current experiment are critically dependent on the accuracy of the model of the processes. If the Exclusion instructions do not manipulate the processes in the assumed manner, or if processes other than those modeled influence performance, then the validity of the conclusions will be compromised. The complexity of the Exclusion instructions makes this problem particularly pertinent. If the subjects did not properly understand the Exclusion instructions, they may have adopted simplifying heuristics for the task at hand. Such heuristics would render the process model inaccurate and compromise the validity of the procedure. The differential effectiveness of the Memory- and Rule-Exclusion instructions across the Incidental and Rule groups, however, suggests that the subjects in the two groups responded to the instructions appropriately.

\section{GENERAL CONCLUSION}

A consistent finding across both experiments was that performance was affected by the similarity of test items to previously encountered training items. The data offer some preliminary insight into the nature of these instance effects. Experiment 1 demonstrated that the instance effects were not necessarily analytic, because categorization was not related to cued recall in the Incidental group, or for Bad analogies in the Rule group. Experiment 2 demonstrated that the instance effects can be influenced by intentional uses of memory. The influence of Bad analogies under Rule-Exclusion conditions suggests that there is probably also an involuntary component to these instance effects. The failure of the process estimation procedure to provide any reliable evidence to support this conclusion most likely reflects several limitations of the estimation procedure.

A number of exemplar models of learning (Kemler Nelson, 1984; J. D. Smith \& Shapiro, 1989; Stanley, Mathews, Buss, \& Kolter-Cope, 1989; Whittlesea \& Dorken, 1993) and automaticity (Logan, 1988) assume that learning involves the automatic retrieval and use of information from memory. It has been difficult to directly test this assumption to date, both because many of these models do not distinguish between automatic and intentional uses of memory and because of problems with existing methodologies (see, e.g., Perruchet \& Pacteau, 1990). The advantage of adopting a dualprocess view of memory is that it provides a framework for understanding the contribution of both intentional and automatic processes. Many contemporary accounts of memory and categorization share common features, such as the distinction between processes based on the retrieval of content specific to individual items and those based on the global matching of features pooled across multiple items (Humphreys, Bain, \& Pike, 1989;
Vokey \& Brooks, 1992). These parallels between memory and categorization phenomena suggest that it may be productive to apply the theories and techniques from one field within the other. The current paper demonstrates that inclusion and exclusion tasks can be used to separate the contribution of different processes to categorization responses, even if some of the stronger assumptions of the estimation procedure are violated.

\section{REFERENCES}

AlleN, S. W., \& Brooks, L. R. (1991). Specializing the operation of an explicit rule. Journal of Experimental Psychology. General, 120, 3-19.

ANDERSON, J. R. (1983). The architecture of cognition. Cambridge, MA. Harvard University Press.

BARGH, J. A. (1989). Conditional automaticity: Varieties of automatic influences in social perception and cognition. In J. S. Ulman \& J. A. Bargh (Eds.), Unintended thought (pp. 3-51). New York: Guilford.

BegG, I. R, ANAS, A., \& Farinacci, S. (1992) Dissociation of processes in belief: Source recollection, statement familiarity, and the illusion of truth. Journal of Experimental Psychology. General, 121, 446-458.

BRoOKs, L. R. (1978). Nonanalytic concept formation and memory for instances. In E. Rosch \& B. Lloyd (Eds.), Cognition and categorization (pp. 169-211). Hillsdale, NJ: Erlbaum.

Brooks, L. R. (1987). Decentralized control of categorization: The role of prior processing episodes. In U. Neisser (Ed.), Concepts and conceptual development Ecological and intellectual factors in categorization (pp. 141-174). Cambridge: Cambridge University Press.

Brooks, L. R., Norman, G. R., \& Allen, S. W. (1991). Role of specific similarity in a medical diagnostic task. Journal of Experimental Psychology. General, 120, 278-287.

CoHen, J., \& Cohen, P. (1983). Applied multiple regression analysis' correlation analysis for the behavioral sciences. Hillsdale, NJ: Erlbaum.

Dunn, J. C., \& Kirsner, K. (1988). Discovering functionally independent mental processes: The principle of reversed association. Psychological Review, 95, 21-101.

Estes, W. K. (1986). Array models for category learning. Cognitive Psychology, 18, 500-549.

Hasher, L., \& ZaCks, R. T. (1979). Automatic and effortful processes in memory. Journal of Experimental Psychology: General, 108, 356-388.

Hayes, N. A., \& Broadbent, D. E. (1988). Two modes of learning for interactive tasks. Cognition, 28, 249-276.

HintzmaN, D. L. (1986). "Schema abstraction" in a multiple trace memory model. Psychological Review, 93, 411-428.

Hintzman, D. L. (1990). Human learning and memory: Connections and dissociations. Annual Review of Psychology, 41, 109-139.

Humphreys, M. S., BaIN, J. D., \& PIKe, R. (1989). Different ways to cue a coherent memory system: A theory for episodic, semantic and procedural tasks. Psychological Review, 96, 208-233.

JACOBY, L. L. (1983). Remembering the data. Analyzing interactive processes in reading. Journal of Verbal Learning \& Verbal Behavior, 22, 485-508.

JACOBY, L. L. (1991). A process dissociatıon framework. Separating automatic from intentional uses of memory. Journal of Memory \& Language, 30, 513-541.

JACOBY, L. L., \& Brooks, L. R. (1984). Nonanalytic cognition. Memory, perception, and concept learning. In G. Bower (Ed.), The psychology of learning and motivation (Vol. 18, pp. 1-47). New York: Academic Press.

JACOBY, L. L., \& DAL.LAS, M. (1981). On the relationship between autobiographical memory and perceptual learning. Journal of Experimental Psychology. General, 110, 306-340.

JaCoby, L. L., Toth, J. P., \& Yonelinas, A. P. (1993). Separating conscious and unconscious influences of memory: Measuring recollection. Journal of Experimental Psychology General, 122, 139-154 
Jacoby, L. L., Woloshyn, V., \& Kel.Ley, C. M. (1989). Becoming famous without being recognized: Unconscious influences of memory produced by dividing attention Journal of Experimental Psychology General, 118, 115-125

JENNINGS, J. M., \& JACOBY, L. L. (1993). Automatic versus intentıonal uses of memory Aging, attention and control. Psychology \& Aging, 8, 283-293.

Kahneman, D., \& Miller, D. T. (1986). Norm theory: Comparing realıty to its alternatıves. Psychological Review, 93, 136-153.

Kemler Nelson, D. G. (1984). The effect of intention on what concepts are acquired. Journal of Verbal Learning \& Verbal Behavior, 23, 734-759.

Klein, G. A., \& Calderwood, R. (1991). Decision models: Some lessons from the field. IEEE Transactions on Systems, Man \& Cybernetics, 21, 1018-1026.

LOGAN, G. D. (1988). Toward an instance theory of automatization Psychological Review, 95, 492-527.

LOGAN, G. D. (1990). Repetition priming and automaticity: Common underlying mechanisms? Cognitive Psychology, 22, 1-35

MANDLER, G. (1980). Recognizing: The judgement of previous occurrence. Psychological Review, 87, 252-271.

McANDrews, M. P., \& MoscovitCH, M. (1985). Rule based and exemplar based classification in artificial grammar learning. Memory \& Cognition, 13, 469-475.

Medin, D. L., \& Schaffer, M. M. (1978). Context theory of classification learnıng. Psychological Review, 85, 207-238.

Medin, D. L., \& Schwanenflugel, P. J. (1981). Linear separability in classification learning. Journal of Experimental Psychology. Human Learning \& Memory, 7, 355-368.

Metcalfe, J., \& Fishir, R. P. (1986). The relation between recognition memory and classification learning. Memory \& Cognition, 14, 164-173.

Morris, C. D., Bransford, J. D., \& Franks, J. J. (1977). Levels of processing versus transfer appropriate processing. Journal of Verbal Learning \& Verbal Behavior, 16, 519-533.

NosoFsKY, R. M. (1986). Attention, similarity and the identificationclassification relationshıp. Journal of Experimental Psychology: General, 115, 39-57.

Nosofsky, R. M. (1988). Exemplar-based accounts of relationships between classification, recognition and typicality. Journal of Experimental Psychology: Learning, Memory \& Cognition, 14, 700708.

Perruchet, P., \& Pacteau, C. (1990). Synthetic grammar learning: Implicit rule abstraction or explicit fragmentary knowledge? Journal of Experimental Psychology: General, 119, 264-275.

REBER, A. S., \& ALLEN, R. (1978) Analogic and abstraction strategies in synthetic grammar learning: A functionalist interpretation. $C o g$ nition, 6, 189-221

Reghr, G., \& Brooks, L. R. (1993). Perceptual manifestations of an analytic structure: The prionty of holistic individuation. Journal of Experimental Psychology. General, 122, 92-114.

Richardson-KLAVEhn, A., \& BJoRK, R. A. (1988). Measures of memory. Annual Review of Psychology, 39, 475-542.

Ross, B. H. (1987). This is like that: The use of earlier problems and the separation of similarity effects. Journal of Experimental Psychology Learning, Memory \& Cognition, 13, 629-639.

Ross, B. H., Perkins, S. J., \& TenPenny, P. L. (1990). Remindingbased category learning. Cognitive Psychology, 22, 460-492.

SCHACTER, D. L. (1987). Implicit memory: History and current status. Journal of Experimental Psychology: Learning, Memory \& Cognition, 13, 501-518.

SCHACTER, D. L., Bowers, J., \& BoOKer, J. (1989). Intention, awareness, and implicit memory: The retrieval intentionality criterion. In S. Lewandowsky, J. C. Dunn, \& K. Kirsner (Eds.), Implicit memory: Theoretical issues (pp. 47-65). Hillsdale, NJ: Erlbaum

SHIFFrIN, R. M., \& SCHNEIDER, W. (1977). Controlled and automatic human information processing: II. Perceptual learning, automatic attending, and a general theory. Psychological Review, 84, 127190.

SMith, E. R., \& ZARATE, M. A. (1990). Exemplar and prototype use in social categorization. Social Cognition, 8, 243-262.

Smith, J. D., \& Shapiro, J. H. (1989). The occurrence of holistic categorization. Journal of Memory \& Language, 28, 386-399.

Stanley, W. B., Mathews, R. C., Buss, R. R., \& Kolter-Cope, S. (1989). Insight without awareness: On the interaction of verbalization, instruction and practice in a simulated process control task. Quarterly Journal of Experimental Psychology, 41A, 553577.

VoKey, J. R., \& BRoOKs, L. R. (1992). The salience of item knowledge in learning artificial grammars. Journal of Experimental Psychology' Learning, Memory, \& Cognition, 18, 328-344.

WATTENMAKER, W. D. (1991). Learning modes, feature correlations and memory-based categorization. Journal of Experimental Psychology: Learning, Memory, \& Cognition, 17, 908-923.

WhitTLESEA, B. W. A., \& Brooks, L. R. (1988). The prionty of particular experiences in the perception of letters, words and phrases. Memory \& Cognition, 16, 387-399.

WhitTLESEA, B. W. A., \& Dorken, M. D. (1993). Incidentally, things in general are particularly determined: An episodic-processing account of implicit learning. Journal of Experimental Psychology: General, 122, 227-248.

\section{NOTE}

1. Baseline values were derived by entering the values representing chance performance in the Inclusion, Memory-Exclusion, and RuleExclusion conditions (.5 probability of approval) into the equations and solving for $\mathrm{Re}, \mathrm{Ru}$, and $\mathrm{A}$.

\section{APPENDIX A}

\section{Abstract Description of Experimental Stimuli}

(a) Experıment 1

\begin{tabular}{|c|c|c|c|c|c|c|c|c|c|c|c|c|c|c|}
\hline & \multirow[b]{2}{*}{$\mathbf{a}$} & \multicolumn{5}{|c|}{ Training Exemplars } & \multirow[b]{2}{*}{ g } & \multirow[b]{2}{*}{$\mathbf{a}$} & \multicolumn{5}{|c|}{ Matching Items } & \\
\hline & & $\mathrm{b}$ & c & d & e & $\mathrm{f}$ & & & $b$ & $\mathrm{c}$ & $\mathrm{d}$ & $\mathrm{e}$ & $f$ & \\
\hline Al & 1 & 1 & 1 & 0 & 0 & 1 & 1 & 1 & 0 & 1 & 0 & 0 & 1 & \\
\hline A2 & 0 & 1 & 1 & 0 & 1 & 2 & 0 & 0 & 0 & 1 & 0 & 1 & 2 & \\
\hline A3 & 1 & 0 & 1 & 1 & 1 & 3 & 1 & 1 & 1 & 1 & 1 & 1 & 3 & \\
\hline A4 & 1 & 1 & 0 & 1 & 0 & 4 & 0 & 1 & 0 & 0 & 1 & 0 & 4 & \\
\hline B1 & 1 & 0 & 0 & 0 & 1 & 3 & 0 & 1 & 1 & 0 & 0 & 1 & 3 & \\
\hline B2 & 0 & 1 & 0 & 1 & 1 & 2 & 1 & 0 & 0 & 0 & 1 & 1 & 2 & \\
\hline B3 & 0 & 0 & 1 & 1 & 0 & 1 & 0 & 0 & 1 & 1 & 1 & 0 & 1 & \\
\hline B4 & 0 & 0 & 0 & 0 & 0 & 4 & 1 & 0 & 1 & 0 & 0 & 0 & 4 & \\
\hline
\end{tabular}

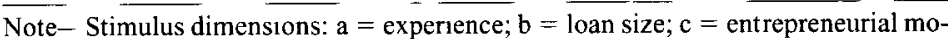
tivation; $d=$ source of other finance; $\mathrm{e}$ suburb; $\mathrm{f}=$ business type; $\mathrm{g}=$ gender. 


\section{Appendix A (Continued)}

(b) Experiment 2

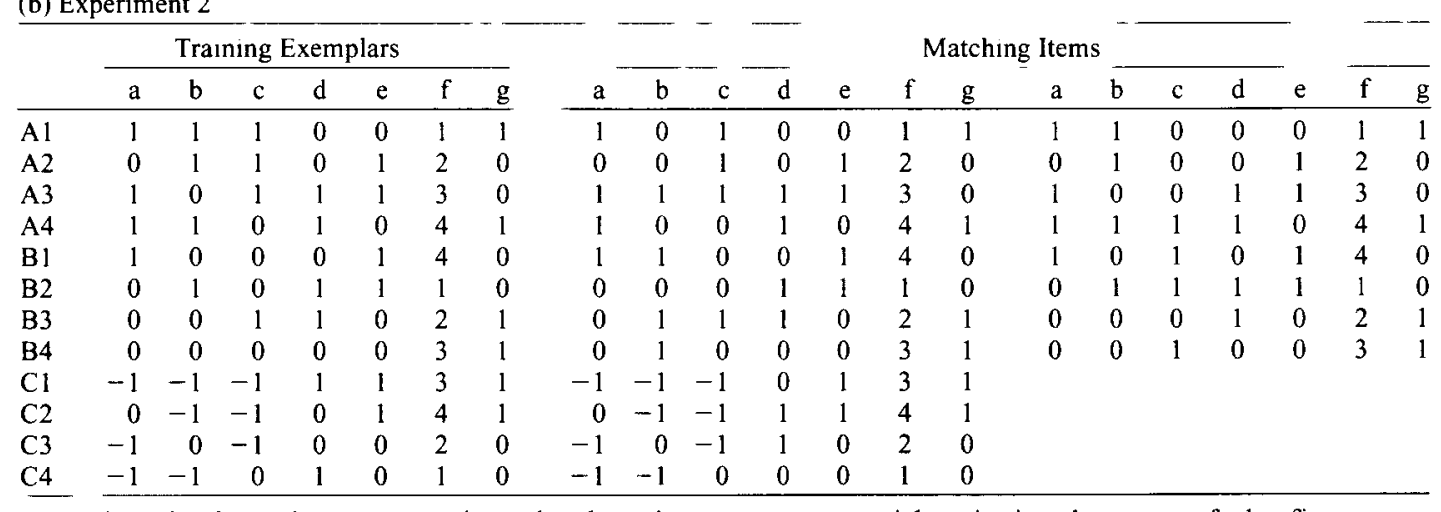

Note - Stimulus dimensions: $a=$ experience; $b=$ loan size; $c=$ entrepreneurial motivation, $d=$ source of other finance; $e=$ suburb; $f=$ business type; $g=$ gender.

\section{APPENDIX B}

\section{Process Dissociation Equations}

The equations used for estimating the probabilities of responding on the basis of automatic retrieval (A), conscious recollection ( $\mathrm{Re}$ ), and rule application $(\mathrm{Ru})$ for the Old items and Good analogies are shown below. These equations are derived by solving Equations 1, 2, and 4 simultaneously:

$$
\begin{gathered}
\operatorname{Re}=I_{A}-M_{A}, \\
A=R_{A} /\left(1-I_{A}+R_{A}\right), \\
R u=\left(M_{A}-R_{A}\right) /(1-R e) .
\end{gathered}
$$

The equations used for estimating the probabilities of responding on the basis of automatic retrieval (A), conscious recollection (Re), and rule application $(\mathrm{Ru})$ for the Bad analogies are shown below. These equations are derived by solving Equations 1, 3, and 5 simultaneously.

$$
\begin{gathered}
\operatorname{Re}=I_{A}-M_{S}, \\
A=\left[M_{S}-\operatorname{Ru}(1-R e)\right] /[1-\operatorname{Re}-\operatorname{Ru}(1-\operatorname{Re})], \\
R u=I_{A}-R_{A} .
\end{gathered}
$$

(Manuscript received January 12, 1994; revision accepted for publication May 24, 1994.) 